\title{
Correction to: Novel Risk Engine for Diabetes Progression and Mortality in USA: Building, Relating, Assessing, and Validating Outcomes (BRAVO)
}

\author{
Hui Shao ${ }^{1}$. Vivian Fonseca ${ }^{2} \cdot$ Charles Stoecker $^{1} \cdot$ Shuqian Liu ${ }^{1} \cdot$ Lizheng Shi $^{1}$
}

Published online: 16 May 2019

(c) Springer Nature Switzerland AG 2019

Correction to: PharmacoEconomics (2018) 36:1125-1134

https://doi.org/10.1007/s40273-018-0662-1

An error in the supplementary online appendix has been identified. In eTable 3, column (HbA1c), the parameter of "L1-HbA1c" should be 0.541 .

The original article can be found online at https://doi.org/10.1007/ s40273-018-0662-1.

Electronic supplementary material The online version of this article (https://doi.org/10.1007/s40273-019-00807-3) contains supplementary material, which is available to authorized users.

Lizheng Shi

1shi1@tulane.edu

1 Department of Global Health Management and Policy, School of Public Health and Tropical Medicine, Tulane University, 1440 Canal Street, Suite 1900, New Orleans, LA 70112, USA

2 School of Medicine, Tulane University, New Orleans, LA, USA 